\title{
Analisis Penerapan PSAK No. 45 sebagai Perwujudan Amanah dan Akuntabilitas pada Laporan Keuangan Masjid Al Akbar Surabaya
}

\author{
*Heri Setiawan, Arief Rahman, Kusni Hidayati \\ Program Studi Akuntansi Fakultas Ekonomi dan Bisnis \\ Universitas Bhayangkara, Indonesia
}

DOI: $10.46821 /$ equity.v1i2.180

\begin{abstract}
ABSTRAK
Penelitian ini bertujuan untuk mengetahui penerapan PSAK No.45 sebagai perwujudan amanah dan akuntabilitas pada laporan keuangan Masjid Al Akbar Surabaya. Peneliti melakukan analisis dengan mengumpulkan dan mengidentifikasi mengenai pengelolaan keuangan Masjid Al Akbar Surabaya baik melalui penerimaan maupun pengeluaran, melakukan analisa berdasarkan teori atau tinjauan pustaka terkait dengan PSAK No.45 hingga melakukan perbandingan antara laporan keuangan Masjid Al Akbar Surabaya dengan Laporan berdasarkan PSAK No.45 sampai akhirnya bisa memberikan kesimpulan mengenai penelitian ini. Jenis penelitian ini adalah penelitian deskriptif kualitatif. Metode pengumpulan data berupa Studi kepustakaan, wawancara, observasi, dokumentasi. Hasil Penelitian menunjukkan bahwa penyampaian laporan keuangan Masjid Al Akbar Surabaya disampaikan ketika selesai shalat jumat, namun disampaikan hanya perolehan infaq dari kotak atau sumbangan dalam kurun waktu minggu tersebut. Laporan keuangan yang disajikan Masjid Al Akbar Surabaya berupa laporan neraca dan laporan surplus/defisit dan belum sesuai dengan PSAK No.45 yang terdiri dari Laporan Posisi Keuangan, Akivitas, Arus Kas dan Catatan atas Laporan Keuangan.
\end{abstract}

Kata Kunci: PSAK No.45, Laporan Keuangan, Nirlaba.

\begin{abstract}
This study aims to determine the application of SFAS No.45 as an embodiment of trust and accountability in the financial statements of Al Akbar Mosque in Surabaya. The researcher carried out the analysis by collecting and identifying the financial management of Al Akbar Surabaya both through receipt and expenditure, carrying out analysis based on theory or literature review related to SFAS No. 45 to make a comparison between the financial statements of Al Akbar Mosque in Surabaya and Reports based on SFAS No.45 until finally able to give conclusions regarding this research. This type of research is qualitative descriptive research. Methods of data collection in the form of library studies, interviews, observation, documentation. The results of the study showed that the submission of the financial statements of the AlAkbar Mosque in Surabaya was delivered when Friday prayers were finished, but it was conveyed only the acquisition of information from the box or donations in the period of the week. The financial statements presented by the Al Akbar Surabaya Mosque are in the form of a balance sheet and a report on surplus / deficit and not in accordance with SFAS No. 45 which consists of Financial Position Reports, Activities, Cash Flows and Notes to Financial Statements.
\end{abstract}

Keywords: SFAS No.45, Financial Statements, Non-Profit.

*Corresponding Author:

Email: herisetiawan488@gmail.com 
PENDAHULUAN

Vol. 1 No. 22021

Setiap entitas baik berorientasi laba maupun nirlaba diharapkan dapat memberikan informasi secara transparan dan lengkap sebagai pertanggungjawaban kepada masyarakat umum atas pengelolaan sejumlah dana yang diterima dari masyarakat dalam bentuk laporan keuangan. Masjid merupakan salah satu bentuk Entitas nirlaba. Andikawati dan Winarno (2014) menyatakan Keuangan masjid diperoleh dari berbagai sumber salah satunya dari jamaah. Pengurus atau pengelola masjid tentunya harus bisa menjaga amanah yang telah diberikan oleh masyarakat dalam hal ini mengelola keuangan masjid. Laeli (2017) menyatakan Salah satu bentuk akuntabilitas atau pertanggungjawaban yang harus dilakukan oleh pengurus masjid adalah dengan menyajikan laporan keuangan yang berisi mengenai aktiva, kewajiban, dan informasi lain yang dibutuhkan dalam proses pertanggungjawaban dari pengurus kepada jamaah atau masyarakat.

Untuk memenuhi kepentingan pengguna laporan keuangan yang mengharapkan sebuah pengelolaan dan pelaporan keuangan yang transparan dan akuntabel. Pemerintah mengatur pengelolaan dan pelaporan keuangan dalam PSAK No.45. Pernyataan ini dibuat unutuk mengatur pelaporan keuangan entitas nirlaba. Dengan adanya pedoman pelaporan, diharapkan entitas nirlaba dapat membuat pelaporan yang memiliki relevansi dan daya banding yang tinggi (Gultom, 2015). Berbagai kegiatan yang dilaksanakan di Masjid Al Akbar Surabaya tentunya membutuhkan dana yang tidak sedikit. Pemasukan dan pengeluaran dari berbagai kegiatan tersebut perlu dicatat dengan teliti agar masyarakat bisa mengetahui aliran masuk dan keluar dana pada Masjid Al Akbar Surabaya. Peneliti tertarik meneliti tentang bagaimana penerapan PSAK No.45 sebagai perwujudan amanah dan akuntabilitas pada laporan keuangan Masjid Al Akbar Surabaya

\section{TINJAUAN PUSTAKA}

\section{Pengertian Organisasi Nirlaba}

Organisasi nirlaba merupakan organisasi yang mendukung isu untuk menarik masyarakat umum bersifat tidak komersial, tanpa ada perhatian terhadap hal-hal yang bersifat mencari laba (moneter) (Hasana, 2011).

\section{Pengertian Amanah}

Benar-benar bisa dipercaya. Manusia yang diberi atau dititipi sebuah amanah harus mampu melaksanakan dengan sungguh-sungguh dan dilaksanakan sesuai dengan apa yang sudah diamanahkan kepada kita. (Darimis, 2015).

\section{Pengertian Akuntabilitas}

Akuntabilitas merupakan pertanggungjawaban manajemen atau penerima amanah kepada pemberi amanah atas pengelolaan sumber-sumber daya yang dipercayakan kepadanya baik secara vertikal maupun secara horizontal (Endahwati, 2014).

\section{Pengertian Laporan Keuangan}

Laporan keuangan merupakan sebuah hasil akhir dari proses akuntansi yang dapat digunakan atau dimanfaatkan sebagai sebuah alat untuk berkomunikasi oleh aktivitas perusahaan dengan pihak yang membutuhkan aktivitas tersebut (Nanu, 2011:119). Laporan Keuangan Entitas Nirlaba Berdasarkan PSAK No.45 Meliputi a. Laporan Posisi Keuangan 
b. Laporan Aktivitas

c. Laporan Arus Kas

d. Catatan atas Laporan keuangan.

\section{METODE PENELITIAN}

Pada penelitian ini menggunakan Penelitian deskriptif kualitatif. Jenis Data yang digunakan dalam penelitian ini adalah data kuantitatif dan Data Kualitatif. Sumber Data penelitian ini yaitu Data primer dan Data Sekunder. Teknik pengumpulan data meliputi Studi Kepustakaan, Observasi, Wawancara, Dokumentasi. Teknik analisis dalam penelitian ini Mengumpulkan dan mengidentifikasi dari data pengelolaan keuangan baik penerimaan maupun pengeluaran masjid Al Akbar. Melakukan analisa dan pembahasan berdasarkan teori dan tinjauan pustaka yang terkait dengan PSAK No.45 serta membandingkan antara laporan keuangan masjid Al Akbar Surabaya dengan laporan keuangan berdasarkan PSAK No.45. Memberikan kesimpulan dan saran peneliti mengenai Penerapan PSAK No.45 sebagai perwujudan amanah dan akuntabilitas laporan keuangan Masjid Al Akbar Surabaya.

\section{HASIL DAN PEMBAHASAN}

Sumber penerimaan Masjid Al Akbar Surabaya diantaranya bersumber dari Donatur baik masyarakat umum maupun pegawai atau karyawan Masjid Al akbar Surabaya, dan Bantuan PEMPROV. Pengeluaran-pengeluaran untuk berbagai keperluan atau kegiatan masjid Al Akbar Surabaya diantaranya antara lain digunakan untuk gaji pegawai/karyawan, untuk perawatan gedung, pembelian berbagai peralatan dll. Pengelola masjid Al Akbar Surabaya berusaha menjaga amanah supaya pengelolaan keuangan dan penggunaan atau penyaluran dananya sesuai dengan apa yang dipercayakan masyarakat. Pertanggungjawabannya berupa pembuatan rekapan laporan yang ditanda tangani oleh kepala bidang keuangan dan sekretaris serta direktur utama yang bertanggungjawab penuh atas pengelolaan keuangan. Pencatatan administrasi keuangan bagi bidang keuangan Masjid Al Akbar Surabaya sangat penting sebagai kontrol transparansi agar wewenang tidak disalahgunakan. Penyampaian informasi keuangan berupa perolehan infaq seperti saat shalat jumat biasanya disampaikan atau diumumkan pada saat jumat yang akan datang.

Laporan masjid Al Akbar masih belum memisahkan antara aset neto terikat baik temporer maupun permanen seperti Dana zakat dan Fidyah seharusnya masuk dalam aset neto terikat temporer. Dana titipan dan modal seharusnya dimasukan dalam kategori aset neto terikat permanen.

Laporan masjid Al Akbar tidak merinci akun-akun yang termasuk dalam perubahan aset neto tidak terikat, perubahan aset neto terikat temporer, dan perubahan aset neto terikat permanen.

Masjid Al Akbar selama ini belum membuat laporan Arus Kas. Laporan Arus kas menyajikan penerimaan dan pengeluaran kas terdiri dari Aktivitas Operasi, Aktivitas Investasi dan Aktivitas Pendanaan.

Catatan atas Laporan Keuangan

Catatan A 
Masjid Al Akbar Surabaya menyajikan hibah atau wakaf berupa kas atau aset lain sebagai sumbangan terikat jika hibah atau wakaf tersebut diterima dengan persyaratan yang membatasi penggunaan aset tersebut. Masjid Al Akbar Surabaya menyajikan hibah atau wakaf berupa bangunan dan peralatan sebagai sumbangan tidak terikat kecuali jika ada pembatasan secara eksplisit menyatakan tujuan pemanfaatan aset tersebut dari pemberi sumber daya. Catatan B

Aset neto terikat temporer adalah sebagai berikut :

Dana Zakat dan Fidyah

$\operatorname{Rp} 130.000 .000$

Catatan C

Aset neto terikat permanen dibatasi untuk :

Modal

Rp 260.000.000

Dana Titipan

$\operatorname{Rp} 20.000 .000$

Catatan D

Aset neto yang dibebaskan dari pembatasan atau terjadinya kondisi yang disyaratkan oleh pemberi sumber daya.

Penyaluran sumbangan, qurban, dan zakat

Rp 102.000.000

\section{SIMPULAN}

Berdasarkan hasil analisis yang telah dilakukan oleh peneliti, maka dapat disimpulkan bahwa pengelolaan keuangan Masjid Al Akbar Surabaya sudah dilaksanakan dengan cukup baik, namun dalam penyajian laporan keuangannya masih belum sesuai dengan PSAK No.45. Hal tersebut dapat dilihat dari. Pengelolaan keuangan pada Masjid Al Akbar Surabaya sudah dikelola dengan cukup baik. Dalam pertanggungjawabannya setiap ada transaksi harus diketahui dan disetujui oleh bendahara penerimaan, bendahara pengeluaran, kepala bidang keuangan, sekretaris dan juga direktur utama. Penyampaian informasi keuangan hanya disampaikan ketika selesai shalat jumat namun hanya pendapatan infaq pada shalat jumat tersebut. Laporan keuangan yang telah disajikan oleh masjid Al Akbar Surabaya masih belum sesuai dengan laporan keuangan organisasi nirlaba menurut PSAK No.45. Terdapat perbedaan pos-pos akun dari laporan neraca masjid Al Akbar Surabaya dengan laporan posisi keuangan yang telah disesuaikan dengan PSAK No.45 dan belum merinci perubahan aset neto tidak terikat, perubahan aset neto terikat temporer dan perubahan aset neto terikat permanen pada periode tersebut dan belum membuat laporan arus kas. 


\section{DAFTAR PUSTAKA}

Andikawati, Desy 2014, Laporan Keuangan Lembaga Masjid (Studi Kasus Pada Lembaga Masjid Agung Anaz Mahfudz Dan Masjid Al- Huda Lumajang), Artikel Ilmia Mahasiswa.

Darimis 2015, REM-BEKAS (Revolusi Mental Berbasis Konseling Spritual Teistik): Upaya Membangun Generasi Berkarakter FAST (Fathonah, Amanah, Siddiq, dan Tabligh). Jurnal Ta'dib. Volume 18, No. 1.

Gultom, Ignasisus R 2015, Analisis Penerapan PSAK No.45 Tentang Laporan Keuangan Organisasi Nirlaba dalam Mencapai Transparansi dan Akuntabilitas Kantor Sinode GMIM, Jurnal EMBA, Vol.3, No.4, Hal. 527537.

Harastiana 2015, Pengaruh Penerapan Pernyataan Standar Akuntansi Keuangan 45 (PSAK 45) dan Pengendalian Intern Terhadap Kualitas Informasi Laporan Keuangan, Skripsi, Universitas Islam, Bandung.

IAI 2016, Standar Akuntansi Keuangan Efektif Per 1 Januari 2017, Ikatan Akuntan Indonesia, Jakarta .

Laeli, Yayuk N 2017, Analisis Faktor-faktor yang Mempengaruhi Kualitas Laporan Keuangan Masjid (Studi Masjid di Kota Semarang), Skripsi, Universitas Negeri, Semarang.

Prasetio, Januar E 2017, Tazkiyatun Nafs: Kajian Teoritis Konsep Akuntabilitas, Jurnal Analisa Akuntansi dan Perpajakan, Volome 1, Nomor 1, Hlm. 19- 33.

Sahri 2018, Penafsiran Ayat-ayat Al Qur'an Tentang Amanah Menurut M. Quraish Shihab, Jurnal Madaniyah, Volume 8 Nomor 1.

Shihab, Quraish 2005, Tafsir al Misbah, Pesan, Kesan dan keserasian Al Qur'an, Volume 5, Lentera Hati, Jakarta.

Sugiyono 2013, Metodologi Penelitian Kuantitatif, Kualitatif Dan R\&D. Alfabeta, Bandung. 
Heri Setiawan dkk., Analisis Penerapan PSAK No. 45 sebagai

Equity: Jurnal Akuntansi Perwujudan Amanah dan Akuntabilitas

Vol. 1 No. 22021

Lampiran 1. Perbandingan Format Laporan Keuangan Masjid Al Akbar Surabaya (Laporan Neraca) Tahun 2018 dengan Laporan Keuangan Berdasarkan PSAK No.45 (Laporan Posisi Keuangan)

\begin{tabular}{|c|c|c|c|}
\hline $\begin{array}{c}\text { Laporan Keuangan Masjid Al } \\
\text { Akbar }\end{array}$ & Jumlah & $\begin{array}{l}\text { Laporan Keuangan } \\
\text { Berdasarkan PSAK }\end{array}$ & Jumlah \\
\hline Laporan Neraca & (Dalam & Laporan Posisi Keuangan & (Dalam \\
\hline Perkiraan & Jutaan) & $\mathrm{Pe}$ & Jutaan) \\
\hline Aktiva & & ASET & \\
\hline & & Aset Lancar & \\
\hline Kas & & Kas dan Setara Kas & \\
\hline Kas Lancar & 150 & Kas Lancar & 150 \\
\hline Kas Bank & 180 & Kas Bank & 180 \\
\hline Total uang Muka/Kas Bon & $\mathrm{Rp}$ & & \\
\hline Pengembalian Kas & $\mathrm{Rp}$ & Pengembalian Kas & (3) \\
\hline Total Kas & 362 & Total Kas dan Setara Kas & 327 \\
\hline Piutang & $\mathrm{Rp}$ & Piutang & 13 \\
\hline Persediaan & $\mathrm{Rp}$ & Persediaan & $\mathrm{Rp}$ \\
\hline Asuransi Dibayar Dimuka & $\mathrm{Rp}$ & Asuransi Dibayar Dimuka & $\mathrm{Rp}$ \\
\hline & & Biaya Dibayar Dimuka & $\mathrm{Rp}$ \\
\hline & & Aset Tidak Lancar & \\
\hline Peralatan & 203 & Peralatan & 203 \\
\hline Akumulasi Penyusutan & $\operatorname{Rp}(37,60)$ & Akumulasi Penyusutan & $\operatorname{Rp}(37,60)$ \\
\hline Biaya Dibayar Dimuka & $\mathrm{Rp}$ & & \\
\hline Pembangunan dan Pengembangan & $\mathrm{Rp}$ & Pembangunan dan Pengembangan & $\mathrm{Rp}$ \\
\hline Total Aktiva & Rp 666,40 & Jumlah Aset & Rp 666,40 \\
\hline Hutang/Kewajiban & & LIABILITAS & \\
\hline & & Liabilitas Jangka Pendek & \\
\hline Hutang Usaha & $\mathrm{Rp}$ & Hutang Usaha & 15 \\
\hline Hutang Gaji & $\mathrm{Rp}$ & Hutang Gaji & $\mathrm{Rp}$ \\
\hline Total Infaq Diterima Dimuka & Rp 261,40 & $\begin{array}{l}\text { Total Pendapatan/Infaq Diterima } \\
\text { Dimuka }\end{array}$ & $\operatorname{Rp} 241,40$ \\
\hline Dana Zakat dan Fidyah & & & \\
\hline Dana Zakat Maal & & & \\
\hline Dana Zakat Fitrah & $\mathrm{Rp}$ & & \\
\hline Dana Fidyah & $\mathrm{Rp}$ & & \\
\hline Total Dana Zakat dan Fidyah & 130 & & \\
\hline Total Hutang/Kewajiban & Rp 406,40 & Jumlah Liabilitas & Rp256,40 \\
\hline Modal & 260 & & \\
\hline Laporan Keuangan Masjid Al Akbar & Jumlah & Laporan Keuangan Berdasarkan & Jumlah \\
\hline Laporan Neraca & (Dalam & Laporan Posisi Keuangan & Dalam \\
\hline Perkiraan & Jutaan) & Perkiraan & Jutaan) \\
\hline & & ASET NETO & \\
\hline & & Tidak Terikat & $\mathrm{Rp}$ \\
\hline & & Terikat Temporer (Catatan B) & 130 \\
\hline & & Terikat Permanen (Catatan C) & 280 \\
\hline & & Jumlah Aset Neto & 410 \\
\hline Jumlah Hutang/kewajiban dan Modal & Rp666,40 & Jumlah Liabilitas dan Aset Neto & Rp666,40 \\
\hline
\end{tabular}

Sumber: Data Diolah 
Heri Setiawan dkk., Analisis Penerapan PSAK No. 45 sebagai

Equity: Jurnal Akuntansi Perwujudan Amanah dan Akuntabilitas

Vol. 1 No. 22021

Lampiran 2. Perbandingan Format Laporan Keuangan Masjid Al Akbar Surabaya (Laporan Surplus/Defisit) Tahun 2018 dengan Laporan Keuangan Berdasarkan PSAK No.45 (Laporan Aktivitas)

\begin{tabular}{|c|c|c|c|}
\hline $\begin{array}{c}\text { Laporan Keuangan Masjid Al Akbar } \\
\text { Suraba }\end{array}$ & Jumlah & $\begin{array}{c}\text { Laporan Keuangan Berdasarkan PSAK } \\
\text { No.45 }\end{array}$ & Jumlah \\
\hline Laporan Surplus/Defisit & (Dalam & Laporan Aktivitas & (Dalam \\
\hline \multirow[t]{7}{*}{ Perkira } & Jutaan) & Perkiraan & \multirow[t]{2}{*}{ Jutaan) } \\
\hline & & $\begin{array}{llll}\text { PERUBAHAN } & \text { ASET } & \text { NETO } & \text { TIDAK } \\
\text { TERIKAT } & & & \\
\end{array}$ & \\
\hline & & Pendapatan & \\
\hline & & Sumbangan & \\
\hline & & Pendapatan infaq kotak & $\mathrm{Rp}$ \\
\hline & & Pendapatan infaq lain-lain & $\mathrm{Rp}$ \\
\hline & & Jasa Layanan & \\
\hline Pendapatan Operasional & & Pendapatan Operasional & \\
\hline $\begin{array}{l}\text { Pendapatan infaq penggunaan } \\
\text { fasilitas }\end{array}$ & $\mathrm{Rp} \quad 474$ & Pendapatan infaq penggunaan fasilitas & $\mathrm{Rp} \quad 474$ \\
\hline Pendapatan infq kotak & $\mathrm{Rp}$ & & \\
\hline Infaq santri lembaga pend. \& kajian & $\mathrm{Rp}$ & & \\
\hline Pendapatan infaq lain-lain & $\mathrm{Rp}$ & & \\
\hline Dana bantuan dan donatur & $\mathrm{Rp}$ & & \\
\hline Zakat,waqaf, dan sumbangan & $\mathrm{Rp}$ & & \\
\hline Pendapatan pembatalan pesanan & $\mathrm{Rp}$ & & \\
\hline Infaq penjualan barang dijual & $\mathrm{Rp}$ & Infaq penjualan barang dijual & $\mathrm{Rp}$ \\
\hline Infaq media publikasi & $\mathrm{Rp}$ & Infaq media publikasi & $\mathrm{Rp}$ \\
\hline Total pendapatan operasional & Rp $\quad 818$ & Total pendapatan operasional & 520 \\
\hline & & Lain-lain & \\
\hline & & pendapatan non operasional & $\mathrm{Rp}$ \\
\hline & & Jumlah pendapatan & 621 \\
\hline & & Beban & \\
\hline Biaya operasional & $\operatorname{Rp}(777,60)$ & Biaya Operasional & $\operatorname{Rp}(675,60)$ \\
\hline pendapatan non operasional & $\mathrm{Rp} \quad 10$ & & \\
\hline SURPLUS & Rp $\quad 50,40$ & Penurunan Aset Neto Tidak Terikat & $\operatorname{Rp}(54,60)$ \\
\hline & & $\begin{array}{l}\text { PERUBAHAN ASET NETO } \\
\text { TEMPORER }\end{array}$ & \\
\hline & & Sumbangan & \\
\hline & & dana bantuan dan donatur & $\mathrm{Rp}$ \\
\hline & & zakat,waqaf, dan sumbangan & $\mathrm{Rp}$ \\
\hline & & $\begin{array}{l}\text { Aset neto terbebaskan dari pembatasan } \\
\text { (Catatan D) }\end{array}$ & $\mathrm{Rp} \quad(102)$ \\
\hline $\begin{array}{l}\text { Laporan Keuangan Masjid Al } \\
\text { Akbar }\end{array}$ & Jumlah & $\begin{array}{c}\text { Laporan Keuangan Berdasarkan PSAK } \\
\text { No.45 }\end{array}$ & Jumlah \\
\hline Laporan Surplus/Defisit & (Dalam & Laporan Aktivitas & (Dalam \\
\hline Perki & Jutaan) & Perkiraan & Jutaan) \\
\hline & & Kenaikan aset neto terikat temporer & $\mathrm{Rp}$ \\
\hline & & $\begin{array}{llll}\text { PERUBAHAN } & \text { ASET NETO } & \text { TERIKAT } \\
\text { PERMANEN } & & & \\
\end{array}$ & \\
\hline & & Sumbangan & \\
\hline & & Infaq santri lembaga pendidikan dan kajian & $\mathrm{Rp}$ \\
\hline & & Kenaikan aset neto terikat permanen & $\mathrm{Rp}$ \\
\hline & & KENAIKAN ASET NETO & $\begin{array}{ll}\mathrm{Rp} & 50,40 \\
\end{array}$ \\
\hline & & ASET NETO AWAL TAHUN & Rp 359,60 \\
\hline & & ASET NETO AKHIR TAHUN & $\mathrm{Rp} \quad 410$ \\
\hline
\end{tabular}

\section{Sumber: Data Diolah}


Heri Setiawan dkk., Analisis Penerapan PSAK No. 45 sebagai

Equity: Jurnal Akuntansi

Perwujudan Amanah dan Akuntabilitas

Vol. 1 No. 22021

Lampiran 3. Perbandingan Format Laporan Keuangan Masjid Al Akbar Surabaya dengan Laporan Keuangan Berdasarkan PSAK No.45

(Laporan Arus Kas)

\begin{tabular}{|c|c|c|c|}
\hline Laporan Keuangan Masjid Al & Jumlah & Laporan Keuangan Berdasarkan PSAK No.45 & Jumlah \\
\hline & (Dalam & Laporan Arus Kas & (Dalam \\
\hline Perkiraan & Jutaan) & Perkiraan & Jutaan) \\
\hline & & Kas dari Pendapatan jasa & \\
\hline & & Pendapatan operasional & \\
\hline & & Pendapatan infaq penggunaan fasilitas & 474 \\
\hline & & Pendapatan infaq kotak & $\mathrm{Rp}$ \\
\hline & & Infaq santri lembaga pendidikan \& kajian & $\mathrm{Rp}$ \\
\hline & & Pendapatan infaq lain-lain & $\mathrm{Rp}$ \\
\hline & & Pendapatan pembatalan pesanan & $\mathrm{Rp}$ \\
\hline & & Infaq penjualan barang dijual & $\mathrm{Rp}$ \\
\hline & & Infaq media publikasi & $\mathrm{Rp}$ \\
\hline & & Total pendapatan operasional & 684 \\
\hline & & Kas dari pemberi sumber daya & \\
\hline & & Dana bantuan dan donatur & $\mathrm{Rp}$ \\
\hline & & Zakat,waqaf, dan sumbangan & $\mathrm{Rp}$ \\
\hline & & Penerimaan lain-lain & \\
\hline & & Pendapatan non operasional & $\mathrm{Rp}$ \\
\hline & & $\begin{array}{l}\text { Kas yang dibayar kepada karyawan dan } \\
\text { supplier }\end{array}$ & \\
\hline & & Biaya Operasional & $\operatorname{Rp}(803,60)$ \\
\hline Tidak ada laporan arus kas & & $\begin{array}{l}\text { Kas neto yang diterima (digunakan) untuk } \\
\text { aktivitas operasi }\end{array}$ & $\operatorname{Rp} \quad 24,40$ \\
\hline & & AKTIVITAS INVESTASI & \\
\hline & & Pembelian Peralatan Kantor & $\mathrm{Rp}$ \\
\hline & & Pembelian Peralatan Kebersihan & $\mathrm{Rp}$ \\
\hline & & Pembelian seragam karyawan & $\mathrm{Rp}$ \\
\hline & & Pembelian Kendaraan & $\mathrm{Rp}$ \\
\hline & & $\begin{array}{l}\text { Kas neto yang diterima (digunakan) untuk } \\
\text { aktivitas investasi }\end{array}$ & $\mathrm{Rp}$ \\
\hline & & AKTIVITAS PENDANAAN & \\
\hline & & Pembangunan dan Pengembangan & $\mathrm{Rp}$ \\
\hline Laporan Keuangan Masjid & Jumlah & Laporan Keuangan Berdasarkan PSAK No.45 & Jumlah \\
\hline & (Dalam & Laporan Arus Kas & (Dalam \\
\hline Perkiraan & Jutaan) & Perkiraan & Jutaan) \\
\hline & & Pembayaran kewajiban tahunan & \\
\hline & & Pajak & $(16)$ \\
\hline & & $\begin{array}{l}\text { Kas neto yang diterima (digunakan) untuk } \\
\text { aktivitas pendanaan }\end{array}$ & $\mathrm{Rp}$ \\
\hline & & $\begin{array}{l}\text { KENAIKAN NETO DALAM KAS DAN } \\
\text { SETARA KAS }\end{array}$ & Rp 100,40 \\
\hline & & $\begin{array}{l}\text { KAS DAN SETARA KAS PADA AWAL } \\
\text { TAHUN }\end{array}$ & Rp 226,60 \\
\hline & & $\begin{array}{l}\text { KAS DAN SETARA KAS PADA AKHIR } \\
\text { TAHUN }\end{array}$ & Rp 327 \\
\hline
\end{tabular}

Sumber: Data Diolah 